ASTHMA

\title{
Underdiagnosed asthma in South Australia
}

\section{R J Adams, D H Wilson, S Appleton, A Taylor, E Dal Grande, C R Chittleborough, R E Ruffin}

Thorax 2003:58:846-850

See end of article for authors' affiliations ....................

Correspondence to: Dr R J Adams, The Health Observatory, The Queen Elizabeth Hospital, University of Adelaide, Woodville, South Australia 5011;

Robert.adams@nwahs.sa. gov.au

Revised version received 23 December 2003 Accepted for publication 9 June 2003

\begin{abstract}
Background: The prevalence of undiagnosed asthma in the general population and the clinical and demographic characteristics of these patients compared with those with diagnosed asthma are unclear. Methods: The North West Adelaide Health Survey (NWAHS) is a population household interview survey of adults (age $>18$ years) in the north western suburbs of Adelaide, South Australia (regional population 0.6 million). Data obtained were weighted to the closest census data to provide population representative estimates. Positive answers to: "Have you ever had asthma?"; "Has it been confirmed by a doctor?"; "Do you still have asthma?" determined current physician diagnosed asthma. A positive bronchodilator response on spirometric testing according to ATS criteria without a physician's diagnosis determined undiagnosed asthma. Other measures included the SF-12 health survey questionnaire, the Selim index of severity of chronic lung disease, skin allergy tests, and demographic data.

Results: Of the 3422 individuals interviewed, $2523(74 \%)$ agreed to participate in the clinical assessment. Of these, 292 (11.6\%) had asthma, 236 (9.3\%) with a doctor's diagnosis of asthma and $56(2.3 \%)$ with undiagnosed asthma defined on spirometric criteria; thus, $19.2 \%$ of the total asthma group were undiagnosed. Those undiagnosed were more likely $(p<0.05)$ to be $>40$ years old, on government benefits, with an income <AUD $\$ 40000$. Symptom frequency was similar in the two asthma groups, but mean spirometric values were lower in the undiagnosed group $(p<0.05)$ while positive skin allergy tests were more common in the diagnosed group $(p<0.05)$. SF-12 component summary scores were significantly lower in both asthma groups than in the non-asthma population. Undiagnosed asthma was frequent in men and in those aged $>65$ years. Health service use over the previous year was similar for both asthma groups.

Conclusion: Undiagnosed asthma is common among the Australian population, with a similar clinical spectrum to those with diagnosed asthma.
\end{abstract}

U ncontrolled asthma can be associated with an increased decline in forced expiratory volume in 1 second $\left(\mathrm{FEV}_{1}\right)$ that may result in chronic airflow limitation. ${ }^{1}$ There is evidence that early intervention in asthma, particularly with inhaled corticosteroids, has a substantial impact on later morbidity. ${ }^{23}$ Identifying people with undiagnosed asthma has the potential to reduce the impairment in health and functional status associated with this condition.

The prevalence of undiagnosed airflow obstruction has been described in several European countries ${ }^{4-9}$ and the US, ${ }^{9}$ and estimates have varied widely from $3.2 \%$ to $11.8 \%$. These studies have been limited to older populations, few have separated chronic obstructive pulmonary disease (COPD) from asthma, and there is limited information on the health and functional impact of undiagnosed asthma. There have been marked differences in the severity of disease found in the undiagnosed groups between various studies.4589 Belousova et al reported that $3 \%$ of an adult Australian population aged $30-50$ years had asymptomatic airway hyperresponsiveness, assessed by a positive histamine challenge test or a positive bronchodilator response. ${ }^{10}$ They did not report on the concurrent clinical impact on these people. The clinical importance of undiagnosed asthma remains uncertain, and therefore the role of screening programmes remains controversial. ${ }^{11}$

We have examined this issue using data from The North West Adelaide Health Study (NWAHS), a representative biomedical population study of people aged 18 years or older living in the north west area of Adelaide, South Australia. In this analysis we describe the prevalence of asthma and compare the demographic characteristics, lung function, symptoms, quality of life status, and health service use of those with self-reported doctor diagnosed asthma and those with undiagnosed asthma.

\section{METHODS}

\section{Sample population}

The North West Adelaide Health Study (NWAHS) is a representative biomedical population study of people aged 18 years or older living in the north western suburbs of Adelaide, South Australia (regional population 0.6 million). This area was considered a priority study area because of previous self-report evidence concerning the high levels of chronic disease and risk factors in the region compared with the rest of the state. ${ }^{12}$ Over $56 \%$ of adults in the region have two or more cardiovascular risk factors, including $40 \%$ with four or more such risk factors. ${ }^{13}$ In addition, measures of social disadvantage have identified parts of this region with greater relative social disadvantage than many other areas of South Australia. ${ }^{14}$ The aims of the study were to provide estimates of diabetes, asthma, and COPD and associated risk factors and quality of life for the northern and western regions of Adelaide. A further aim of the study was to provide an estimation of previously undiagnosed rates of these diseases and a demographic description and risk factor profile of the groups of concern.

\section{Study design}

Households selected at random from the electronic white pages telephone directory were interviewed by telephone and recruited to a clinical assessment. In each selected household the person aged 18 years or older who was last to have a birthday was asked to participate. The study was performed from February to December 2000. Telephone interviews by 
trained health interviewers investigated self-reported health status, mental health, smoking status, and demographic variables. Of the 3422 individuals interviewed, 2523 (74\%) agreed to participate in the clinical assessment. A questionnaire was then sent to each participant for self-completion. This comprised items on the frequency of alcohol consumption, exercise patterns, more detailed demographic information, health service use, the SF-36 questionnaire, and the Selim Index of Chronic Lung Disease (CLD).

The Selim CLD Index is made up of six items that form three subscales: frequency and intensity of dyspnoea; frequency and intensity of wheezing; frequency of coughing and amount of sputum production over the past 3 months. ${ }^{15}$ The CLD Index has been validated in US and Australian population studies. ${ }^{15}{ }^{16}$ It has shown a high level of agreement with clinical data, including peak flow measurements. ${ }^{15}$ The index is scored out of 100, and the result is categorised into mild $(\leqslant 43)$, moderate (44-62), and severe $(>62)$ levels of severity. ${ }^{15}$ These categories have demonstrated discriminative value between different levels of chronic lung disease that impact on quality of life across physical and mental health scales. ${ }^{16}$

Medical assessment comprised spirometric tests, blood pressure measurement, height, weight, waist and hip measurements, fasting blood, and allergy skin tests to rye grass, cat, house dust mite, Alternaria, feather, and cockroach. Spirometric tests were conducted at the two hospitals according to American Thoracic Society criteria. ${ }^{17}$

To determine doctor diagnosed asthma, participants were asked if they had ever had asthma, whether a doctor confirmed their asthma, and if they still had asthma. Individuals with current asthma were defined as those who reported having been told by a doctor they had asthma or those who had a $15 \%$ increase in forced expiratory volume in l second $\left(\mathrm{FEV}_{1}\right)$ following a bronchodilator, or those who had a $12 \%$ increase in $\mathrm{FEV}_{1}$ following a bronchodilator if the absolute difference in $\mathrm{FEV}_{1}$ was greater than $200 \mathrm{ml}$. Undiagnosed asthma was defined by a positive acute bronchodilator response on spirometric testing in those who did not report a doctor's diagnosis of asthma. No measurements of non-specific airway hyperresponsiveness were made.

\section{Statistical analysis}

Data were analysed using SPSS version 10.0. Differences in proportions were assessed for significance using $\chi^{2}$ tests and Mantel-Haenszel methods for analysis of $2 \times k$ tables.

Standardised scores for the SF-36 questionnaire were calculated after the method of Garrett at al. ${ }^{18}$ Standard scores were calculated for each health summary scale by dividing the difference in the quality of life score by the standard deviation of the population summary scale. The mean of the general state population was set at zero for each summary score, allowing comparisons to be made with each of the asthma groups in terms of standard deviations. Kazis et al ${ }^{19}$ discuss the techniques for interpreting the differences between groups in standard scores. An effect size of 0.2 is described as small or mild, 0.4 as moderate, and $\geqslant 0.8$ as large.

Approval for the NWAHS study was obtained from the institutional ethics committees at the two hospitals involved.

\section{RESULTS}

Of the 2523 adult participants, 292 (11.6\%) had asthma. Of these, $236(9.3 \%)$ had a self-reported doctor's diagnosis of asthma and $56(2.3 \%, 95 \%$ CI 1.7 to 2.9$)$ were unaware of the diagnosis and were defined as having asthma on spirometric criteria. Thus, $19.2 \%$ of the total asthma group had undiagnosed asthma. Table 1 shows the demographic
Table 1 Demographic characteristics of the sample population according to asthma diagnosis (\%)

\begin{tabular}{|c|c|c|c|}
\hline & $\begin{array}{l}\text { Diagnosed } \\
\text { asthma } \\
\text { ( } n=236 \text { ) }\end{array}$ & $\begin{array}{l}\text { Undiagnosed } \\
\text { asthma }(n=56)\end{array}$ & $\begin{array}{l}\text { No asthma } \\
(n=2231)\end{array}$ \\
\hline \multicolumn{4}{|l|}{ Age } \\
\hline$\geqslant 40$ years $\dagger$ & 48.3 & 76.8 & 55.4 \\
\hline$<40$ years $\dagger$ & 51.7 & 23.2 & 44.6 \\
\hline Sex (\% male) & 37.3 & 46.4 & 50.3 \\
\hline \multicolumn{4}{|l|}{ Marital status } \\
\hline Married/partner & 65.7 & 67.9 & 62.2 \\
\hline $\begin{array}{l}\text { Divorced/ } \\
\text { widowed/never } \\
\text { married }\end{array}$ & 34.3 & 32.1 & 37.8 \\
\hline \multicolumn{4}{|l|}{ Country of birth } \\
\hline Australia† & 80.1 & 60.7 & 69.3 \\
\hline Immigrantt & 19.9 & 39.3 & 30.7 \\
\hline \multicolumn{4}{|l|}{ Income } \\
\hline$<$ AUD\$40000t & 51.7 & 80.4 & 48.2 \\
\hline$>$ AUD\$40000t & 48.3 & 19.6 & 51.8 \\
\hline \multicolumn{4}{|l|}{$\begin{array}{l}\text { Social Security } \\
\text { pension }\end{array}$} \\
\hline Yest & 38.6 & 51.8 & 31.0 \\
\hline \multicolumn{4}{|l|}{ Employment } \\
\hline Not working & 38.6 & 64.3 & 35.3 \\
\hline Working currently & 61.4 & 35.7 & 64.7 \\
\hline \multicolumn{4}{|c|}{ Education } \\
\hline High school only & 53.0 & 50.0 & 47.6 \\
\hline Post high school & 47.0 & 50.0 & 52.4 \\
\hline \multicolumn{4}{|l|}{ Atopy* } \\
\hline Yes† & 74.6 & 57.1 & 57.9 \\
\hline
\end{tabular}

*Atopy $=$ skin test reactions of $>2 \mathrm{~mm}$ to rye grass, cat, house dust mite, Alternaria, feather, and cockroach allergens.

$+p<0.05$ for difference diagnosed $v$ undiagnosed asthma.

characteristics of the groups with asthma compared with those without asthma. Bivariate analyses showed that subjects with previously undiagnosed asthma were significantly more likely than those with self-reported diagnosed asthma to be aged over 40 years, to be born outside Australia, to be retired or undertaking home duties, to be receiving a social security pension, and to have an annual income of $<$ AUD\$40 000 (table 2). Those with diagnosed asthma were significantly more likely to be atopic with positive skin reactions to one or more of rye grass, house dust mite, and Alternaria allergens. A multiple logistic regression model showed that undiagnosed asthma was independently associated with being male (OR 2.1, 95\% CI 1.2 to 3.6), age $>40$ years (OR 2.4, 95\% CI 1.1 to 5.5 ), income <AUD $\$ 40000$ (OR 3.9, 95\% CI 1.7 to 8.7), and being born outside Australia (OR 2.0, 95\% CI 1.1 to 3.7). Table 3 shows the prevalence of health risk factors according to asthma diagnosis.

The symptom burden of asthma was assessed by the Selim Index of Chronic Lung Disease (table 4). The distribution of the frequency of symptoms over the previous 3 months was similar in the diagnosed and undiagnosed asthma groups, and both groups were significantly different $(\mathrm{p}<0.05)$ from the no asthma population. Lung function results are shown in table 5. The group with undiagnosed asthma had significantly lower mean spirometric values than those with a self-reported diagnosis of asthma $(\mathrm{p}<0.01$ for all comparisons between diagnosed and undiagnosed asthma).

The quality of life in individuals with asthma was more impaired than in those without asthma. On SF-36 scale scores, asthma had a severe effect on general health and a moderate effect on physical functioning, role-physical, vitality and mental health. Previously undiagnosed asthma had a significant effect on quality of life in subjects aged 65 years and older and also in men on the physical health scales $(\mathrm{p}<0.05)$, with a severe effect on physical functioning and a moderate effect on role-physical, general health and vitality. Table 6 shows the component summary scores 


\begin{tabular}{|c|c|c|c|c|}
\hline Variable & Category & Odds ratio & $95 \% \mathrm{Cl}$ & $p$ value \\
\hline \multirow[t]{2}{*}{ Age } & $<40$ years & 1.0 & & \\
\hline & $>40$ years & 3.5 & 1.7 to 7.7 & $<0.001$ \\
\hline \multirow[t]{2}{*}{ Sex } & Female & 1.0 & & \\
\hline & Male & 1.5 & 0.8 to 2.7 & 0.2 \\
\hline \multirow[t]{2}{*}{ Marital status } & Single & 1.0 & & \\
\hline & Married & 1.1 & 0.6 to 2.5 & 0.8 \\
\hline \multirow[t]{2}{*}{ Birthplace } & Australia & 1.0 & & \\
\hline & Overseas & 2.6 & 1.3 to 5.1 & $<0.01$ \\
\hline \multirow[t]{2}{*}{ Income } & $\geqslant \$ 40000$ & 1.0 & & \\
\hline & $<\$ 40000$ & 3.8 & 1.8 to 8.3 & $<0.001$ \\
\hline \multirow[t]{2}{*}{ Government benefits } & No pension & 1.0 & & \\
\hline & Pension & 1.7 & 1.0 to 3.2 & 0.05 \\
\hline \multirow[t]{2}{*}{ Employment } & Employed & 1.0 & & \\
\hline & Not working & 1.6 & 0.9 to 3.2 & 0.1 \\
\hline \multirow[t]{2}{*}{ Education } & Post school & 1.0 & & \\
\hline & High school only & 0.9 & 0.5 to 1.7 & 0.7 \\
\hline Atopy & Yes & 0.45 & 0.24 to 0.87 & 0.009 \\
\hline
\end{tabular}

according to age and sex. Figure 1 shows standardised scores for the SF-36 physical and mental component summaries unadjusted for age and sex and when controlled for age and sex. This shows a significant effect of asthma in terms of the burden of illness, as shown by reductions in mean physical component summary scores in both the diagnosed and undiagnosed asthma groups. As the differences in scores are seen in the elderly and in men, it can be seen that, in population terms, most of the burden for the undiagnosed asthma group can be accounted for by age and sex, with the adjusted scores being similar to the group without asthma . Mental health scores were also affected by asthma. When adjusted for age and sex, mean mental component summary scores were significantly lower in the undiagnosed asthma group than in the population without asthma.

Subjects with asthma used more health services than those without asthma, particularly general practitioner, hospital emergency department, and hospital outpatient clinic services in South Australia (table 7). Individuals with both diagnosed and undiagnosed asthma had a significantly higher mean number of visits to general practitioners and a higher proportion of frequent $(\geqslant 7)$ visits over the previous year than others $(\mathrm{p}<0.05)$. The mean number of hospital outpatient clinic visits was also significantly higher in both the undiagnosed and diagnosed asthma groups than in the general population, although this did not reach statistical significance.

\begin{tabular}{|c|c|c|c|}
\hline & $\begin{array}{l}\text { Diagnosed } \\
\text { asthma }(n=236)\end{array}$ & $\begin{array}{l}\text { Undiagnosed } \\
\text { asthma }(n=56)\end{array}$ & $\begin{array}{l}\text { No asthma } \\
\text { ( } n=2231)\end{array}$ \\
\hline \multicolumn{4}{|l|}{ Smoking: } \\
\hline $\begin{array}{l}\text { Current smoker } \\
\text { Alcohol: }\end{array}$ & 24.2 & 21.4 & 27.0 \\
\hline $\begin{array}{l}\text { Intermediate to } \\
\text { very high risk }\end{array}$ & 7.6 & 1.8 & 6.6 \\
\hline $\begin{array}{l}\text { Blood pressure: } \\
\text { High BP } \\
(>140 / 90)^{*}\end{array}$ & 25.8 & 45.5 & 27.5 \\
\hline Cholesterol: & & & \\
\hline $\begin{array}{l}\text { High total lipids } \\
\text { (>5.5 mmol) }\end{array}$ & 31.8 & 32.7 & 37.2 \\
\hline $\begin{array}{l}\text { Activity levels: } \\
\text { Insufficient/none }\end{array}$ & 50.0 & 47.3 & 48.0 \\
\hline $\mathrm{BMI}>30 \mathrm{~kg} / \mathrm{m}^{2 *}$ & 34.7 & 26.8 & 27.9 \\
\hline
\end{tabular}

\section{DISCUSSION}

Our results indicate that up to one in five people with probable asthma in this population did not report a confirmed diagnosis of asthma. Those in the group with undiagnosed asthma are not merely people with mild lung function abnormalities without implications for health status. Their lung function was significantly worse than those with diagnosed asthma, with implications for increased mortality. ${ }^{20}$ The spectrum of symptoms was similar to those with diagnosed asthma, and was worse than the rest of the population. In the undiagnosed asthma group much of the extra burden in terms of quality of life was seen in the elderly and in men. There is a significant overall quality of life burden of illness attributable to undiagnosed asthma. It is clear that undiagnosed asthma represents a substantial health burden to the community.

To address the health burden first requires the identification of individuals with asthma. Those with undiagnosed asthma tended to be older immigrant men on lower incomes who were also significantly more likely to suffer from uncontrolled high blood pressure than the rest of the population. A similar proportion to the general population continued to smoke. It is also this group who are suffering the greatest impairment in quality of life. However, this group is not invisible to the healthcare system. Subjects with undiagnosed asthma visited their general practitioner and hospital outpatient clinics as often as those with diagnosed asthma. These results suggest that, in part, extra vigilance from clinicians in all sectors will be required to address the

Table 4 Percentage of individuals in each category of lung symptom severity assessed by the Selim Index of Chronic Lung Disease* according to asthma diagnosis

\begin{tabular}{llll}
\hline & \multicolumn{3}{l}{ Selim Chronic Lung Disease } \\
\cline { 2 - 4 } & Mild & Moderate & Severe \\
\hline $\begin{array}{l}\text { Diagnosed asthma } \\
(n=236)\end{array}$ & 71.4 & 20.9 & 7.7 \\
$\begin{array}{l}\text { Undiagnosed asthma } \\
(n=56)\end{array}$ & 73.2 & 19.7 & 7.1 \\
$\begin{array}{l}\text { No asthma ( } n=2231) \\
\text { Total }(n=2523)\end{array}$ & 93.9 & 5.0 & 1.1 \\
\hline
\end{tabular}

*The Selim CLD Index is a 6 item questionnaire with three subscales of dyspnoea, wheezing, and cough/sputum. The index is scored out of 100 categorised into mild $(\leqslant 43)$, moderate $(44-62)$, and severe $(>62)$ levels of severity. ${ }^{15}$ 
Table 5 Mean (SD) pre-bronchodilator and postbronchodilator spirometric values according to asthma diagnosis*

\begin{tabular}{|c|c|c|c|}
\hline & $\begin{array}{l}\text { Diagnosed } \\
\text { asthma }\end{array}$ & $\begin{array}{l}\text { Undiagnosed } \\
\text { asthma }\end{array}$ & No asthma \\
\hline Pre FEV $1(1 / s)$ & 2.75 (1.02) & $1.96(0.79)$ & $3.17(0.93)$ \\
\hline $\begin{array}{l}\% \text { predicted Pre } \\
\text { FEV }\end{array}$ & 89.8 & 72.2 & 100.1 \\
\hline Post FEV 1 & $2.89(1.03)$ & $2.32(0.87)$ & $3.26(0.96)$ \\
\hline $\begin{array}{l}\% \text { predicted Post } \\
\mathrm{FEV}_{1}\end{array}$ & 94.7 & 84.9 & 100.7 \\
\hline Pre FVC (I) & $3.43(1.15)$ & $2.75(0.99)$ & $3.81(1.08)$ \\
\hline $\begin{array}{l}\% \text { predicted Pre } \\
\text { FVC }\end{array}$ & 94.4 & 81.9 & 100.7 \\
\hline Post FVC & $3.52(1.12)$ & $3.04(0.93)$ & $3.83(1.09)$ \\
\hline $\begin{array}{l}\text { \% predicted Post } \\
\text { FVC }\end{array}$ & 97.1 & 91.1 & 101.2 \\
\hline
\end{tabular}

$\mathrm{FEV}_{1}=$ forced expiratory volume in 1 second; $\mathrm{FVC}=$ forced vital capacity. ${ }^{*} \mathrm{p}<0.01$ for all comparisons between diagnosed and undiagnosed asthma.

problems arising from these chronic diseases. In addition, approaches that use community screening and improved media publicity may make asthma symptoms and required action more salient to the general population.

It is possible that clinicians are less likely to consider asthma to be of significance in older people. In a population survey of older adults in Bristol, UK, Dow et al found that $2.4 \%$ of men had untreated asthma, most of whom had moderate or severe disease. ${ }^{21}$ Dickinson et al screened 353 asymptomatic elderly patients aged $60-75$ years in a semirural general practice and identified eight (2.3\%) with undiagnosed asthma, but few had significant symptoms. ${ }^{7}$ Coultas et al reported data from the NHANES III survey of 5743 white adults aged 45 years and older in the US and found undiagnosed airflow obstruction in $12.0 \%$ with only $2.7 \%$ reporting doctor diagnosed asthma. ${ }^{9}$ Dyspnoea was reported by over $50 \%$ of those with an $\mathrm{FEV}_{1}<75 \%$ of predicted. ${ }^{9}$ Our results suggest that spirometric screening in primary care should be considered for all smokers and anyone with chest symptoms. Studies examining the cost effectiveness of community screening with spirometric tests are needed.

Socioeconomic differences in asthma diagnostic labelling have been reported in UK children ${ }^{22}$ but have not been well described in adults. Part of this phenomenon may relate to differences in the presentation with respiratory symptoms to GPs, which can contribute significantly to the problem of underdiagnosis of asthma. ${ }^{23}$ Further work is needed to determine whether there are socioeconomic or demographic differences in the presentation of asthma symptoms to GPs.

A number of studies in selected populations have relied on symptoms to establish the frequency of undiagnosed asthma. Hahn and Beasley ${ }^{24}$ found that $3.4 \%$ of adults in a general practice population in Wisconsin had symptoms consistent

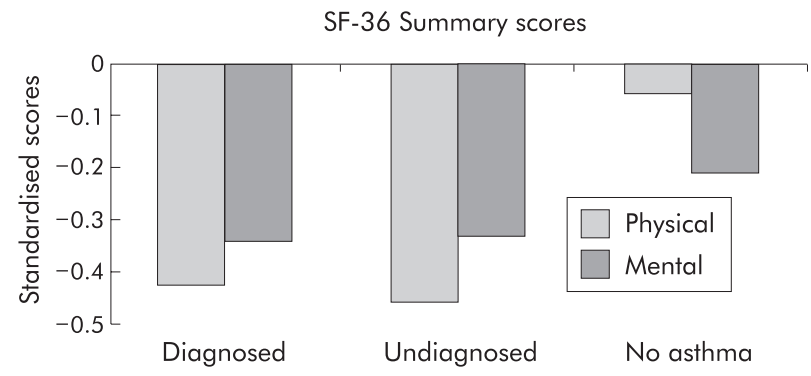

SF-36 Summary scores, controlling for age and sex

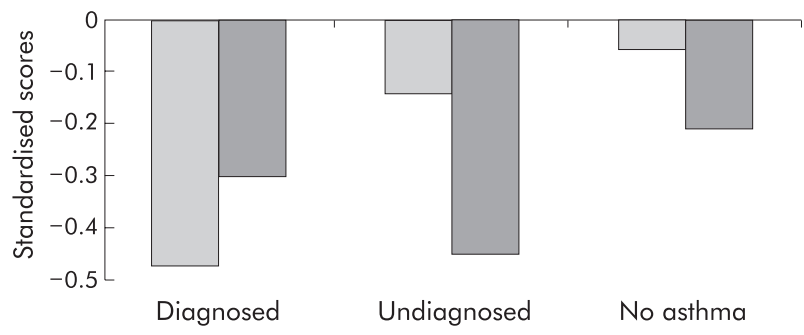

Figure 1 Effect of asthma on SF-36 physical component summary (PCS) and mental component summary (MCS) scores. Scores are shown as $z$ scores, standardised to the population mean score.

with asthma, without a diagnosis having been made. De Marco et $a l^{25}$ reported that asthma was greatly underdiagnosed in Italy, and Nish and Schiewtz ${ }^{26}$ reported that a diagnosis of asthma had not previously been considered in $30 \%$ of young airmen with physiological abnormalities, most of whom had mild and primarily exercise induced asthma. Results from the European Community Respiratory Health Survey show that the prevalence of asthma-like symptoms is much greater than that of physician diagnosed asthma, ${ }^{27}$ but the prevalence of lung function abnormalities consistent with asthma in the undiagnosed group was not reported. Our finding that people with undiagnosed asthma have a spectrum of disease similar to that of diagnosed asthmatics has not been well described previously.

Our study was limited by the self-reporting of a prior asthma diagnosis before recruitment. We did not have information from GP or hospital records to confirm whether asthma had previously been diagnosed and the individual was unaware of that fact. However, it can be argued that, if someone is either unaware or denies that he or she has asthma, it is not a salient issue; it is unlikely that effective management will occur, and the potential exists for adverse health consequences. Self-reports of doctor diagnosed asthma have a high specificity when validated in relation to either airway hyperresponsiveness or a clinical diagnosis of

Table 6 SF-36 physical and mental component summary scores* by age groups according to asthma diagnosis

\begin{tabular}{|c|c|c|c|c|c|c|}
\hline & \multicolumn{3}{|c|}{ Physical component summary } & \multicolumn{3}{|c|}{ Mental component summary } \\
\hline & Diagnosed & Undiagnosed & None & Diagnosed & Undiagnosed & None \\
\hline \multicolumn{7}{|c|}{ Age (years) } \\
\hline$<40$ & $48.9(9)$ & $56.1(1)$ & $52.3(7)$ & $46.7(9)$ & $46.6(8)$ & $47.0(11)$ \\
\hline $40-64$ & 43.4 (11) & $47.0(10)$ & $47.9(9)$ & $46.7(9)$ & 45.0 (13) & $49.2(10)$ \\
\hline$\geqslant 65$ & $37.0(11)$ & $37.0(11)$ & $40.9(10)$ & $50.4(12)$ & $50.0(10)$ & $51.8(10)$ \\
\hline \multicolumn{7}{|l|}{ Sex } \\
\hline Male & $47.4(11)$ & $42.0(11)$ & $48.9(9)$ & $47.2(11)$ & $48.2(11)$ & $49.7(10)$ \\
\hline Female & $43.7(11)$ & 47.1 (12) & $48.3(9)$ & 47.5 (9) & $46.9(10)$ & 47.6 (11) \\
\hline
\end{tabular}

*Population mean score set at 50 with a standard deviation of 10 . 
Table 7 Use of health services over the previous 12 months according to asthma diagnosis

\begin{tabular}{|c|c|c|c|}
\hline & $\begin{array}{l}\text { Diagnosed } \\
\text { asthma }\end{array}$ & $\begin{array}{l}\text { Undiagnosed } \\
\text { asthma }\end{array}$ & No asthma \\
\hline \multicolumn{4}{|c|}{ General practitioner visits } \\
\hline Mean (SD) & $7.1(6.4)$ & $8.7(14.9)$ & $4.8(6.5)$ \\
\hline $0-2$ visits (\%) & 20.3 & 35.7 & 40.7 \\
\hline $3-6$ visits (\%) & 41.9 & 26.8 & 41.5 \\
\hline$\geqslant 7$ visits (\%) & 37.7 & 37.5 & 17.7 \\
\hline \multicolumn{4}{|c|}{ Emergency department visits } \\
\hline Mean (SD) & $0.36(0.98)$ & $0.19(0.69)$ & $0.16(0.56)$ \\
\hline$\%$ with $\geqslant 1$ visit & 20.8 & 10.0 & 11.7 \\
\hline \multicolumn{4}{|c|}{ Hospital outpatient or specialist clinic visits } \\
\hline Mean (SD) & $3.3(3.6)$ & $3.4(2.8)$ & $2.8(3.4)$ \\
\hline
\end{tabular}

asthma, ${ }^{28}$ so we would expect only a small number of those reporting diagnosed asthma not to have the condition.

It is likely that our prevalence figures for undiagnosed asthma are an underestimate of the true situation as reversibility to bronchodilators is a relatively insensitive test for making a diagnosis. ${ }^{29}{ }^{30}$ There are likely to be people who narrowly fail to attain the criteria for significant reversibility on the one occasion but who have asthma. However, for the study to have comparable and robust results, it is necessary to state the criteria for categorising people with asthma according to accepted guidelines. Measures of non-specific airway hyperresponsiveness ${ }^{31}$ or diurnal variability in peak flow measurements may identify a further group of people with undiagnosed asthma. Such measures would also help to determine if any of those in the undiagnosed asthma group were poor perceivers of airway obstruction. This phenomenon has been reported to occur in around $15 \%$ of people with asthma $^{32}$ and may also account, to some extent, for the fact that asthma has not been diagnosed in these people.

Despite the inclusion of a relatively large number of subjects in this study, the absolute numbers with undiagnosed asthma were not large. However, the confidence intervals around this estimate were relatively small, indicating the robustness of the prevalence estimates. The strength of this study is that it is a large random sample of people in this region. The consistency of the pattern of characteristics of asthma between the diagnosed and undiagnosed asthma groups suggests that the study is providing an accurate picture of undiagnosed asthma in the community. The north west Adelaide region is one of relative social disadvantage compared with the rest of Adelaide. It is possible that areas with a different social mix may provide different results. However, the region remains diverse in terms of all the sociodemographic characteristics measured. A number of studies have shown that socioeconomically disadvantaged groups are at risk for adverse asthma outcomes. It is therefore reasonable to examine issues that may be contributing to poorer outcomes in such populations.

The first step in the Australian National Asthma Council guidelines states the need to establish the diagnosis of asthma. It is clear that, over a decade after the promulgation of national guidelines for asthma management, we continue to fail to achieve this first step for a substantial number of people. The burden to individuals and to the community from undiagnosed asthma demands a targeted effort to correct this problem. A focus on older men may be the first action needed.

\section{Authors' affiliations}

R J Adams, D H Wilson, S Appleton, R E Ruffin, The Health Observatory, The Queen Elizabeth Hospital, University of Adelaide, Woodville, South Australia
A Taylor, E Dal Grande, C R Chittleborough, Population Research and Outcome Studies Unit, Department of Human Services, South Australia

\section{REFERENCES}

1 Lange P, Parner J, Vestbo J, et al. A 15-year follow-up study of ventilatory function in adults with asthma. N Engl J Med 1998;339:1 194-200.

2 Boushey HA. Glucocorticoid therapy for chronic obstructive pulmonary disease. N Engl J Med 1999;340:1990-1.

3 Haahtela $T$, Jarvinen $M$, Kava $T$, et al. Comparison of a beta2-agonist, terbutaline, with an inhaled corticosteriod, budesonide, in new detected asthma. N Eng J Med 1991;325:388-92.

4 Isoaho R, Puolijoki H, Huhti E, et al. Prevalence of chronic obstructive pulmonary disease in elderly Finns. Respir Med 1994;88:571-80.

5 Renwick DS, Connolly MJ. Prevalence and treatment of chronic airways obstruction in adults over the age of 45. Thorax 1996;51:164-8.

6 van den Boom G, van Schayck CP, van Mollen MP, et al. Active detection of chronic obstructive pulmonary disease and asthma in the general population. Am J Respir Crit Care Med 1998;158:1730-8.

7 Dickinson JA, Meaker M, Searle M, et al. Screening older patients for obstructive airways disease in a semi-rural practice. Thorax 1999;54:501-5.

8 Bannerjee DK, Lee GS, Malik SK, et al. Underdiagnosis of asthma in the elderly. Br J Dis Chest 1987;81:23-9.

9 Coultas DB, Mapel D, Gagnon R, et al. The health impact of undiagnosed airflow obstruction in a national sample of United States adults. Am J Respir Crit Care Med 2001; 164:372-7.

10 Belousova EG, Haby MM, Xuan W, et al. Factors that affect normal lung function in white Australian adults. Chest 1997; 112:1539-46.

11 Crockett A. Screening older patients for obstructive airways disease. Thorax 1999:54:472-3.

12 Adams R, Ruffin R, Wakefield $M$, et al. Asthma prevalence, morbidity and management practices in South Australia, 1992-1995. Aust NZ J Med 1997;27:672-9.

13 Taylor A, Dal Grande E, Chittleborough C, et al. The North West Adelaide Health Study: key biomedical findings, policy implications and research recommendations. Adelaide: South Australia Department of Human Services, 2002.

14 Australian Bureau of Statistics. 1996 census of population and housing: socioeconomic indexes for areas, ABS Catalogue No. 2039.0. Canberra: ACT, 1998.

15 Selim AJ, Ren XS, Fincke G, et al. A symptom-based measure of the severity of chronic lung disease: results from the Veterans Health Study. Chest 1997;111:1607-14.

16 Ruffin RE, Wilson D, Chittleborough CR, et al. Multiple respiratory symptoms predict quality of life in chronic lung disease: a population-based study of Australian adults. Qual Life Res 2000/9:1031-9.

17 American Thoracic Society. Standardization of spirometry: 1987 update. Am Rev Respir Dis 1987; 136:1285-98.

18 Garrett AM, Ruta DA, Abdalla MI, et al. The SF-36 health survey questionnaire: an outcome measure suitable for use routine use within the NHS? BMJ 1993;306:1440-4.

19 Kazis L, Anderson JJ, Meenan RF. Effect sizes for interpreting changes in health status. Med Care 1989;27(Suppl):S178-89.

20 Knuiman $M W$, James $A L$, Divitini $M L$, et al. Lung function, respiratory symptoms, and mortality: Results from the Busselton Health Study. Ann Epidemiol 1999;9:297-306.

21 Dow L, Fowler L, Phelps $L$, et al. Prevalence of untreated asthma in a population sample of 6000 older adults in Bristol, UK. Thorax 2001;56:472-6

22 Ng Man Kwong G, Das C, Proctor AR, et al. Diagnostic and treatment behaviour in children with chronic respiratory symptoms: relationship with socioeconomic factors. Thorax 2002:57:701-4.

23 van Schayck CP, van der Heijden FMMA, van den Boom G, et al Underdiagnosis of asthma: is the doctor or the patient to blame? The DIMCA project. Thorax 2000;55:562-5.

24 Hahn DL, Beasley JW. Diagnosed and possible undiagnosed asthma: a Wisconsin Research Network (WReN) Study. Wisconsin Research Network (WReN) Asthma Prevalence Study Group. J Fam Pract 1994;38:373-9.

25 de Marco R, Cerveri I, Bugiani M, et al. An undetected burden of asthma in Italy: the relationship between clinical and epidemiological diagnosis of asthma. Eur Respir J 1998;11:599-605.

26 Nish WA, Schwietz LA. Underdiagnosis of asthma in young adults presenting for USAF basic training. Ann Allergy 1992;69:239-42.

27 Janson C, Chinn S, Jarvis D, et al. Physician-diagnosed asthma and drug utilization in the European Community Respiratory Health Survey. Eur Respir J 1997; 10:1795-802.

28 Toren J, Brisman J, Jarvholm B. Asthma and asthma like symptoms in adults assessed by questionnaires. Chest 1993:104:600-8.

29 Connolly MJ, Kelly C, Walters HE, et al. An assessment of methacholine inhalation tests in elderly asthmatics. Age Ageing 1998;17:123-8.

30 Prior JG, Cochrane GM. Assessment of optimum dose of inhaled terbutaline in patients with chronic asthma. The use of simple cumulative dose response curves. Br J Dis Chest 1982;72:266-8.

31 O'Connor GT, Sparrow D, Weiss ST. A prospective study of methacholine airway responsiveness as a predictor of pulmonary function decline: the Normative Aging Study. Am Rev Respir Dis 1990;141:87-92.

32 Rubinfeld AR, Pain M. Perception of asthma. Lancet 1976:882-4. 